\title{
Association between food availability and young people's fruits and vegetables consumption: understanding the mediation role of the theory of planned behaviour
}

\author{
May Oo Lwin ${ }^{1, *}$, Shelly Malik' and Jerrald Lau ${ }^{2}$ \\ 'Wee Kim Wee School of Communication and Information, Nanyang Technological University, 637718 Singapore: \\ ${ }^{2}$ Saw Swee Hock School of Public Health, National University of Singapore, Singapore
}

Submitted 4 March 2019: Final revision received 4 December 2019: Accepted 20 December 2019: First published online 26 May 2020

\begin{abstract}
Objective: To evaluate the relationship between fruits and vegetables (F\&V) availability at home and young people's F\&V consumption behaviour, and how the theory of planned behaviour (TPB) constructs could potentially mediate the relationship.

Design: Cross-sectional face-to-face survey questionnaire to assess the TPB constructs and home food availability assessed using open inventories method. F\&V availability was categorised into low and high levels based on median split. Setting: Singapore.

Participants: Two hundred and ten households (each consisting one parent-child pair) recruited via stratified cluster sampling with child participants ranging from 9 to 16 years of age.

Results: Mediation analyses were conducted using structural equation modelling. The relationship between home F\&V availability and F\&V consumption behaviour did not have a significant direct association, but there were significant indirect effects through the routes of perceived behavioural control (PBC) and intention as well as attitude and intention. Specifically, higher level of F\&V availability at home was related to more positive PBC and attitude towards F\&V, and subsequently greater intention to consume $F \& V$ and higher consumption of $F \& V$. Conclusions: Parents should make F\&V more readily available at home as increased exposure to F\&V could be related to enhanced liking, sense of control and intention to consume F\&V and facilitate children's healthy diet.
\end{abstract}

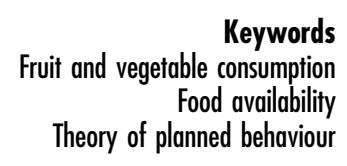

The steady increase in obesity rates among young people (i.e. children and adolescents) in many developed countries has been a priority issue for health authorities. According to the Global Burden of Disease Study, the prevalence of overweight and obese young people in developed countries was approximately $23.8 \%$ for males and $22.6 \%$ for females in $2013^{(1)}$. Among the Singapore population, the obesity rate has risen consistently from $5.1 \%$ in 1992 to $8.7 \%$ in 2017 , with projections of further growth to $15 \cdot 0 \%$ by $2024^{(2,3)}$. Childhood obesity has been associated with a range of health issues such as type 2 diabetes and $\mathrm{CVD}^{(4,5)}$, in addition to mental health concerns such as decreased self-esteem and depression ${ }^{(5,6)}$. Unhealthy weight gain in adolescent years is likely to be carried into adulthood, leading to enhanced risks of certain kinds of cancer and premature death ${ }^{(7,8)}$.
Dietary intake has been acknowledged as a major factor contributing to obesity. Obesity primarily occurs from energy imbalance whereby energy consumption exceeds energy expenditure by the individual, a situation exacerbated by unhealthy eating habits and poor food choices ${ }^{(5,6,9)}$. For young people, food consumption habits have been identified to be a crucial component of regulating this energy balance, which in turn is key to managing the likelihood and severity of obesity both during childhood and into adulthood ${ }^{(6)}$. Building a habit of consuming fruits and vegetables $(\mathrm{F} \& \mathrm{~V})$ has also been identified as a potential way to reduce obesity ${ }^{(10-12)}$. The recommended daily intake of $\mathrm{F} \& \mathrm{~V}$ tends to differ between countries. In the USA, for instance, the United States Department of Agriculture recommends adolescents to consume approximately two cups each of vegetables 
and fruits daily ${ }^{(13)}$, while in Singapore, the daily recommendation is two servings (approximately one-and-a-half cups) each of vegetables and fruits ${ }^{(14)}$. Nonetheless, both adults and young people commonly fail to meet the recommended daily F\&V intake ${ }^{(15,16)}$. For example, it was noted that nine out of ten Singaporeans were not consuming adequate servings of $\mathrm{F} \& \mathrm{~V}^{(17)}$. Identifying the drivers of consumption behaviour for healthy foods, especially $F \& V$, is therefore an area of substantial importance in the interest of developing better health promotion and intervention programmes for young people at risk, due largely to the physiological benefits of adequate $F \& V$ consumption, including decreased risks of life-threatening diseases such as stroke, heart disease and various forms of cancer ${ }^{(18,19)}$. In addition, consistent F\&V consumption has been linked to benefits that persist throughout the lifespan, including slower rates of cognitive decline due to the ageing process ${ }^{(20)}$.

Notably, scholars have observed how psychosocial and environmental factors could differentially affect young people's motivation to eat healthily. Young people's behaviour is not exclusively volitional but also affected by other social and environmental factors. In particular, food availability and accessibility have been found to be regular determinants in influencing healthy food consumption among children ${ }^{(21)}$. In this vein, we plan to assess how the availability of F\&V in home environments will impact the psychosocial drivers, as outlined by the theory of planned behaviour (TPB) ${ }^{(22)}$, of F\&V consumption of young people aged 9-16 years old. While extant research has argued that theoretically grounded interventions have generally been more effective in contributing to the understanding and engagement of the problem of child obesity, research on associated factors such as food availability remains scarce ${ }^{(23-25)}$. In light of the benefits accrued from the establishment of healthful F\&V consumption habits and the urgency underscored by rising child obesity rates, it is crucial for researchers and health authorities to carefully examine the motivating factors that drive $F \& V$ intake among young people. The present study is unique in that while past studies have mainly relied on self-reports of child or parent respondents to determine the level of food availability, our research draws upon an open inventory method where food availability is measured by directly observing the amount of F\&V available in the respondents' home. This method mitigates the potential bias from selfreporting especially as studies have shown that there is a low agreement between young people's and parents' perceived F\&V availability at home ${ }^{(26-28)}$ and social desirability bias from parents' self-report ${ }^{(29)}$.

\section{Theory of planned behaviour and consumption of fruits and vegetables}

The TPB has successfully been utilised in a number of earlier studies examining determinants of food choice intentions and healthful dietary behaviour among children and adolescents ${ }^{(30-33)}$. The TPB consists of three antecedent constructs (attitude, subjective norm and perceived behavioural control (PBC)), intention and actual behaviour. The theory posits that intention and $\mathrm{PBC}$ are direct predictors of actual behaviour. Intention is, in turn, predicted by individuals' attitude towards the behaviour, subjective norm as well as PBC. Attitude is commonly defined as the beliefs held by individuals on the possible consequences of executing the target behaviour as well as the consideration of each consequence's outcome ${ }^{(6,22)}$. Subjective norm is defined as individuals' beliefs about the degree to which significant others would approve or disapprove of the target behaviour and the individual's likelihood of compliance with these others' views ${ }^{(22)}$. PBC refers to the degree to which individuals believe the target behaviour is within their control ${ }^{(19,22)}$. There is considerable support for the TPB as a prediction model ${ }^{(34,35)}$; within the present context of food consumption, meta-analyses by Guillaumie et al. ${ }^{(36)}$ and Riebl et al. ${ }^{(24)}$ have found that the TPB could significantly account for intention and food consumption behaviour in both child and adult samples.

Nonetheless, there have been mixed findings on the influence of each TPB construct on predicting individuals' intention towards consuming F\&V. A number of studies among youth posit that attitude is the most significant antecedent-driving intention and food consumption behaviour for $F \& V^{(6,37)}$. For example, a meta-analysis of how the TPB has been utilised to examine young people's dietary behaviours by Riebl et al. ${ }^{(24)}$ found that while all three antecedent constructs were significant contributors to intention, attitude remained the strongest predictor. Similarly, a systematic review and meta-analysis of the relationship between TPB and diet patterns by McDermott et al. ${ }^{(38)}$ suggested that intention was most significantly associated with attitude, followed by PBC and subjective norm. Some of these differences can probably be explained by the age of the respondents. McDermott et al. ${ }^{(38)}$ noted that PBC was more significantly associated with consumption behaviour for younger (17 years or less) rather than older individuals (aged 18-29 years and over 30 years, respectively) in the included studies. However, even among young people, literature studying the influence of TPB constructs on the food consumption of children and adolescents has produced mixed findings. Although most studies agree that attitude tends to be the strongest predictor, there is a lack of consensus on the significance of other TPB constructs. While a handful of studies have proposed PBC as the next strongest determinant of intention ${ }^{(39,40)}$, others disagree ${ }^{(41,42)}$. The relationship between F\&V dietary intention and behaviour has not been consistent, either; while some studies found significant associations $^{(43,44)}$, others did not show such relationship ${ }^{(37,45)}$. This lack of consensus across the literature suggests the influence of other factors in how TPB constructs drive food consumption behaviour ${ }^{(37,46)}$. 


\section{The Environmental Research framework for weight Gain prevention and the role of home food availability}

In addition to intrapersonal factors, environmental factors have been considered as important determinants of food consumption behaviours ${ }^{(47,48)}$. One conceptual model that attempts to integrate the influence of environmental factors on individuals' energy balance-related behaviours (e.g. food consumption) is the Environmental Research framework for weight Gain prevention (EnRG). Under EnRG, the environment (e.g. physical, socioeconomic) is posited to have both a direct effect and an indirect effect - through the mediation of intrapersonal constructs from theories of behaviour change such as the TPB - on the target behaviour. The EnRG has been widely used to study a variety of relationships pertaining to energy balance-related behaviours, including the influence of the food/exercise environment on adults' weightregulation activities, and associations between the school food environment and adolescents' unhealthy food consumption behaviours $^{(49,50)}$

EnRG has also been used as a model to conceptualise the various components of a young person's home food environment within the context of healthy eating ${ }^{(51)}$. Among these, availability and accessibility of F\&V have consistently been suggested to be an important environmental factor that is significantly associated with young people's F\&V consumption behaviour ${ }^{(21,52-55)}$. In view of the lack of uniformity among researchers with regard to the construct of food availability ${ }^{(56)}$, the present study defines availability as food that is physically present within the household ${ }^{(57)}$. Prior research has shown that availability to healthy foods at home is positively associated with intake of these foods among young people and $\operatorname{adults}^{(46,58)}$, although other research has found limited evidence in the association between household food environment and F\&V intake ${ }^{(48,59)}$. Nonetheless this relationship is complex. For example, Kratt et al. ${ }^{(60)}$ found that households with more F\&V available tended to have significant stronger psychosocial motivating factors (such as outcome expectations, behavioural capability and knowledge) for both parents' and young people's consumption of healthy food than in families with low F\&V availability. Tak et $a l .^{(61)}$, on the other hand, found that neither home nor neighbourhood F\&V availability was directly or indirectly associated with adults' F\&V consumption behaviours, although the authors suggested that a lack of variation in environments between participants may have influenced these outcomes. Furthermore, food availability at home has been put forth as a possible driver of outcome of school-based healthful eating interventions for young people ${ }^{(60,62)}$; Bere \& Klepp ${ }^{(63)}$ showed that changes in children's accessibility to F\&V both at home and in school were linked with general $F \& V$ intake. These findings have been echoed in Blanchette \&
Brug's structured review of factors that determine F\&V intake among children ${ }^{(21)}$. While evidence suggested that factors such as parent's F\&V intake, knowledge of healthful consumption and television viewing had an influence on child F\&V consumption, availability and accessibility remained the most consistent determinants ${ }^{(21,64)}$.

While studies have examined F\&V availability and accessibility as an environmental influence on food consumption behaviours of both adults and young people, much of extant work has been atheoretical ${ }^{(21,49,50,55)}$. Also relatively unknown are the mechanisms by which $F \& V$ availability at home influences F\&V intake among young people. The present study therefore attempts to build on existing research by exploring the associations (i) between home F\&V availability and F\&V consumption among young people (the EnRG direct effect), (ii) between the TPB constructs and F\&V consumption and (iii) whether the association of home F\&V availability with $\mathrm{F} \& \mathrm{~V}$ consumption is mediated by any of the TPB constructs (the EnRG indirect effect). Figure 1 shows the conceptual framework. Following the EnRG model, we hypothesise that home F\&V availability (the environmental factor) will be directly as well as indirectly linked to $\mathrm{F} \& \mathrm{~V}$ consumption (the energy balancerelated behaviour) through one or more of the TPB constructs (the intrapersonal mediators).

\section{Method}

\section{Participants}

A total of 210 households consisting of young people (the child participant; $n$ 210) with their parents (the parent participant; $n$ 210) were recruited using stratified cluster sampling in Singapore. Household eligibility was based on two factors. Parent participants had to be either a Singaporean citizen or permanent resident, while the child participants were required to be from grades 4 to 9 . Each household was provided with a \$S30 participation incentive (approximately equivalent to \$US23).

\section{Procedure}

From a list of all government schools in Singapore, we split the schools into the thirty-four urban residential planning regions demarcated by the Urban Redevelopment Authority ${ }^{(65)}$. Schools were randomly stratified and selected from within each of these regions. The data collection process began by identifying the housing apartment block with the smallest property number adjacent to the selected school premises. Researchers then proceeded to the top floor of the apartment block and started from the household with the smallest unit number. If they faced an unsuccessful attempt, the researchers skipped one unit. At the end of every floor, the researchers descended one level and the process was repeated.

For each participating household, the researcher first surveyed the child participant and then the home food 


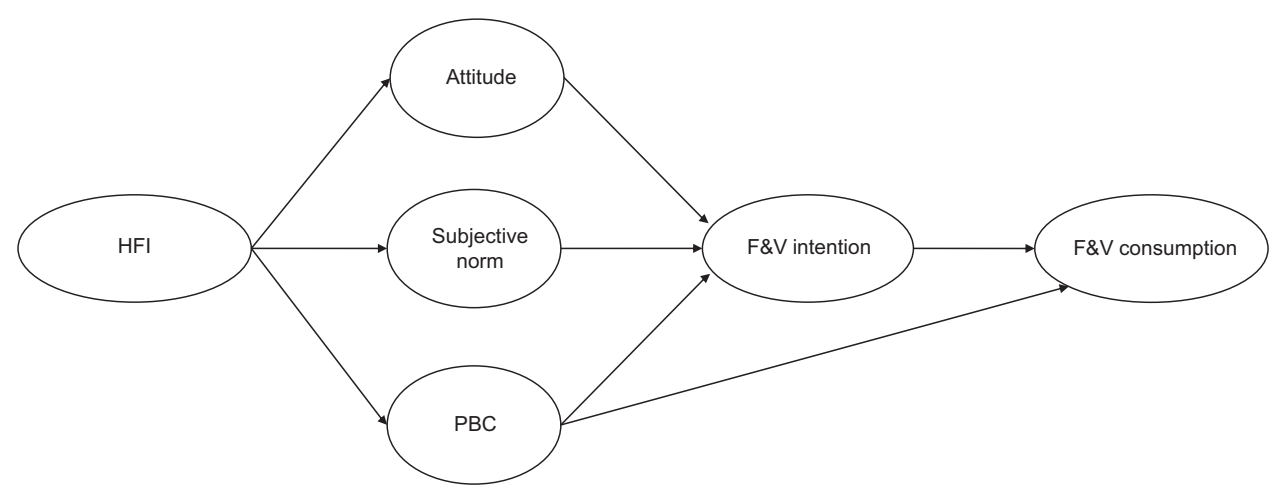

Fig. 1 Conceptual framework of the mediated effect of theory of planned behaviour constructs in the association between $\mathrm{HFI}$ and food consumption behaviour. HFI, home fruits and vegetables inventory; F\&V, fruits and vegetables; PBC, perceived behavioural control

inventory. The child surveys were conducted in a common area of the household such as the living room, with the parent participant allowed to be present during the process for reassurance. Parent participants were requested to refrain from influencing their child's survey responses.

The home food inventory was catalogued by providing the parent participant with a set of five size-standardised zip-lock bags. Parent participants were then instructed by the researcher to examine each food item in their pantry and select the bag size that would best fit the total amount of said item. The researcher assisted with the recording of the bag sizes selected, and the unpacking and repacking of each food item to-and-from storage areas where necessary within each household.

\section{Materials}

\section{Child survey}

The child questionnaire examined food consumption behaviour and intention with regard to $\mathrm{F} \& \mathrm{~V}$, and TPB constructs including attitude, subjective norm and PBC towards healthy food. The food consumption behaviour and intention scales consisted of four items adapted from food intake studies ${ }^{(66-68)}$, with two items (one for fruits and the other for vegetables) in each category (consumption and intention). Food consumption behaviour items were worded with the following: 'How often do you eat the following items during a typical week?' to which participants responded on a nine-point scale ranging from 'more than or equal to five servings per day' (1) to 'never' (9). These items were reverse coded in the analysis so that higher scores represented higher levels of consumption and then recoded into approximate servings per day based on the National Cancer Institute's All-Day Screener for F\&V consumption $^{(69,70)}$. Intention items were worded as 'I intend to consume the following items next week', with response categories ranging from strongly disagree (1) to strongly agree (5). Participants' attitude towards healthy food were measured using four items on positive affect adapted from Aikman et $a l{ }^{(71)}$. The items were presented immediately below four full colour pictures of
F\&V items. Each item was typically worded as such: 'I feel happy when I eat the above food'. Subjective norm towards $\mathrm{F} \& \mathrm{~V}$ were examined using six items adapted from Fishbein \& Ajzen ${ }^{(72)}$. Sample items include 'Many people like me eat the above food every week' and 'Many people like me think that I should eat the above food every week'. Lastly, the PBC scale towards F\&V consisted of four items (e.g. 'It is mostly up to me whether or not I eat the above food every week'), also adapted from Fishbein \& Ajzen ${ }^{(72)}$. For the attitude, subjective norm and PBC measures, participants responded using a five-point scale ranging from strongly disagree (1) to strongly agree (5).

\section{Home fruits and vegetables inventory}

With the assistance of the researchers as detailed above, parent participants undertook an inventory count of food in their pantry. The food inventory was developed from checklists used in prior nutrition and obesity studies and consisted of fifty-eight pre-defined food items ${ }^{(73,74)}$. Amounts were determined using a seven-point scale by selecting a 'best fit' size for the total volume of each food type present, with reference taken from a set of five standardised zip-lock bags (320, 760, 1290, 3330 and $4800 \mathrm{ml}$ ). The two other options were for sizes 'smaller than $320 \mathrm{ml}$ ' (1) and 'larger than $4800 \mathrm{ml}$ ' (7). In order to be able to quantify and create one measure of home F\&V inventory (HFI), we considered the size 'smaller than $320 \mathrm{ml}$ ' to be on average half the size of the smallest bag $(320 \mathrm{ml})$, and hence, it was recoded into ' $160 \mathrm{ml}$ '. Likewise, the size 'larger than $4800 \mathrm{ml}$ ' was approximated to be on average twice the size of the largest bag ( $4800 \mathrm{ml}$ ), and hence, recoded as ' $9600 \mathrm{ml}$ '. For the purposes of the present research, only two categories ('Vegetables' and 'Fruits') were used for analysis.

\section{Statistical analyses}

Data entry and analyses were performed using IBM SPSS Statistics for Windows, version $22.0^{(75)}$. Exploratory factor analysis was performed using maximum likelihood extraction with promax rotation for the attitude towards healthy food, subjective norm and PBC scales, followed by reliability analysis of these constructs. The items from each of the 
TPB constructs were found to group into their respective factors, and hence, they were averaged to create the TPB measures. The four attitude items formed one composite variable (Cronbach's $\alpha=0 \cdot 87$ ), with higher scores representing more positive attitude towards healthy food. The six subjective norm items were composited into a single variable (Cronbach's $\alpha=0 \cdot 86$ ). One out of the four items on the PBC scale had a low factor loading and, hence, was excluded from further analysis. The remaining three items were composited into one PBC variable (Cronbach's $\alpha=0 \cdot 80$ ). The two F\&V items each for behavioural consumption were summed to create a composite measure for F\&V consumption $(r 0.477, P<0.001)$. The two items for intention were averaged to derive the F\&V consumption intention measure $(r 0.458, P<0.001)$. The HFI scores for $\mathrm{F} \& \mathrm{~V}$ were then summed to derive the composite measure of HFI $(M=9455.3 \mathrm{ml}, \mathrm{SD}=6504.3 \mathrm{ml}$, median $=$ $8865.0 \mathrm{ml}, \min =0 \mathrm{ml}, \max =19200 \mathrm{ml}$ ). As HFI was measured based on the 'best fit' size of standardised zip-lock bags, which was an ordinal scale, we divided the composite HFI measure into two groups based on median split following the method used in prior nutrition studies ${ }^{(68,76,77)}$ and to allow for parsimony in the analysis, that is, low HFI $(M=3933.2 \mathrm{ml}, \mathrm{sD}=2898,4 \mathrm{ml}, \min =0 \mathrm{ml}, \max =8130 \mathrm{ml})$ and high HFI $(M=14977.4 \mathrm{ml}, \mathrm{SD}=3878,7 \mathrm{ml}, \mathrm{min}=9600$ $\mathrm{ml}, \max =19200 \mathrm{ml}$ ).

Multiple regression was performed to assess the direct association between $F \& V$ availability at home and F\&V consumption behaviour. Structural equation modelling was conducted using the AMOS module version 24.0 to examine the mediating effect of the TPB constructs on the relationship between home $F \& V$ availability and F\&V consumption behaviour. In order to perform mediation analyses with multiple mediators, we followed the bootstrapping method as recommended by Preacher \& Hayes $^{(78)}$. The bootstrap estimates in this study were based on 2000 samples. The existence of mediation was determined based on whether the indirect effects were statistically significant at 95\% CI. Age and gender were included in the above analyses as control. Statistical significance for all analyses was defined at $P<0.05$.

\section{Results}

\section{Participants' characteristics}

As can be seen in Table 1, of the 210 household units, the household sample comprised $73.0 \%$ Chinese, $10.0 \%$ Malay, $13.5 \%$ Indian and $3.5 \%$ other races, which closely resembled that of Singapore's national ethnic distribution $^{(65)}$. The child sample consisted of $45.7 \%$ female and $54.3 \%$ male, aged $9-16$ years old ( $M_{\text {age }}$ of child participant $=13.08$ years). As shown in Table 2 , the mean consumption of F\&V was 3.20 servings per day (SD $2 \cdot 13$ ), while the mean score for intention to consume F\&V was $4 \cdot 10$ (SD 0.84).
Table 1 Description of demographics of the study sample (N210)

\begin{tabular}{lrr}
\hline & $n$ & $\%$ \\
\hline $\begin{array}{lrr}\text { Gender } \\
\text { Male }\end{array}$ & 114 & \\
Ethnicity & & $54 \cdot 3$ \\
$\quad$ Chinese & 154 & $73 \cdot 0$ \\
$\quad$ Malay & 21 & $10 \cdot 0$ \\
Indian & 28 & 13.5 \\
$\quad$ Other & 7 & 3.5 \\
Home F\&V availability (HFI) & & \\
$\quad$ Low & 105 & $50 \cdot 0$ \\
$\quad$ High & 105 & $50 \cdot 0$ \\
Mean age & & \\
$\quad$ Mean & $13 \cdot 1$ & \\
SD & $1 \cdot 7$ & \\
\hline
\end{tabular}

$\mathrm{F} \& \mathrm{~V}$, fruits and vegetables.

Table 2 Mean scores and SD for the theory of planned behaviour constructs $(n 210)$

\begin{tabular}{lcc}
\hline & Mean & SD \\
\hline Attitude & 3.55 & 0.77 \\
Subjective norm & 4.23 & 0.75 \\
PBC & 4.03 & 0.64 \\
F\&V intention & 4.10 & 0.84 \\
F\&V consumption & 3.20 & $2 \cdot 13$
\end{tabular}

PBC, perceived behavioural control; F\&V, fruits and vegetables.

Item response categories for all constructs (except F\&V Consumption) were presented using Likert-type scales ranging from 'strongly disagree' (1) to 'strongly agree' (5). Responses for F\&V consumption items were converted to servings consumed per day (ranging from 0 to 5 servings).

\section{Correlations and regression}

Table 3 shows the Pearson's correlation results between the TPB constructs and F\&V consumption intention and behaviour. HFI was significantly associated only with $\mathrm{F} \& \mathrm{~V}$ consumption intention $(P<0.001)$, but not with F\&V consumption behaviour nor any of the TPB constructs. As expected, attitude, subjective norm and PBC were highly correlated to each other and to F\&V consumption intention $(P<0.001)$. In turn, intention was associated with F\&V consumption behaviour $(r 0.332, P<0.001)$. While there were significant associations between attitude and $\mathrm{PBC}$ and F\&V consumption behaviour $(r=0.292, P<0.001)$, subjective norm was not significantly associated with F\&V consumption behaviour. The multiple regression analysis to examine the direct association between F\&V availability at home and F\&V consumption behaviour with age and gender entered as control variables revealed no significant association.

\section{Path analysis}

To assess the mediating effect of the TPB constructs on the relationship between HFI and F\&V consumption intention and behaviour, structural equation modelling analysis was performed based on the conceptual framework illustrated in Fig. 1. Gender and age were included in the path analysis as control variables. The measures for the model fit of the conceptual framework (as shown in Fig. 2) suggest an 
Table 3 Correlations between variables

\begin{tabular}{|c|c|c|c|c|c|c|}
\hline & $\begin{array}{c}\text { F\&V } \\
\text { consumption }\end{array}$ & $\begin{array}{c}\text { F\&V } \\
\text { intention }\end{array}$ & Attitude & $\begin{array}{l}\text { Subjective } \\
\text { norm }\end{array}$ & PBC & $\mathrm{HFI}$ \\
\hline F\&V consumption & 1.00 & & & & & \\
\hline F\&V intention & $0.33^{\star \star \star}$ & 1.00 & & & & \\
\hline Attitude & $0.24^{\star \star \star}$ & $0.47^{\star \star \star}$ & 1.00 & & & \\
\hline Subjective norm & 0.06 & $0.42^{\star \star \star}$ & $0.35^{\star \star \star}$ & 1.00 & & \\
\hline PBC & $0.29^{\star \star \star}$ & $0.48^{\star \star \star}$ & $0.50^{\star \star \star}$ & $0.53^{\star \star \star}$ & 1.00 & \\
\hline $\mathrm{HFI}$ & 0.05 & $0 \cdot 23^{\star \star \star}$ & 0.11 & 0.07 & 0.13 & 1.00 \\
\hline
\end{tabular}

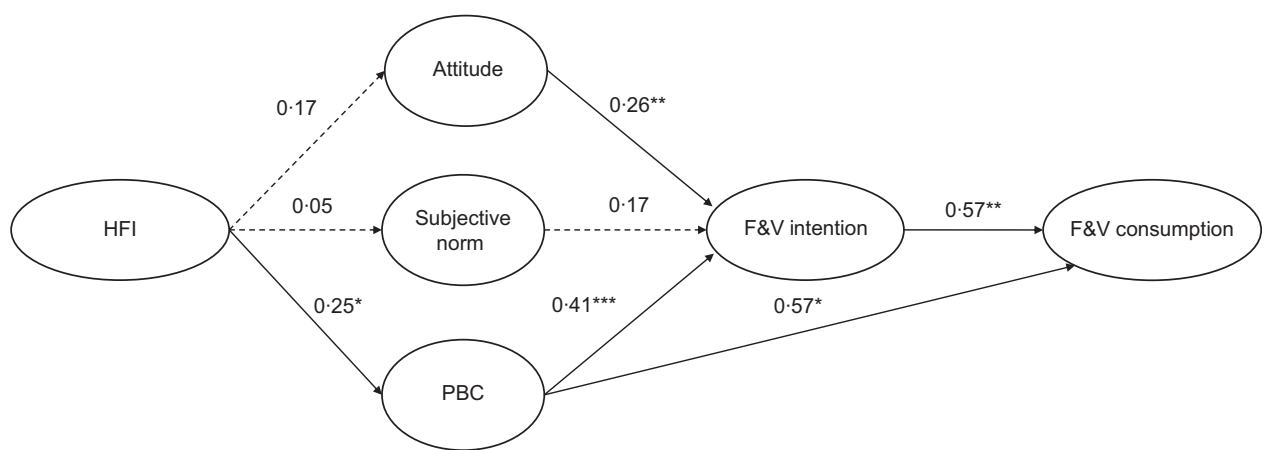

Fig. 2 The path analysis for the relationship between HFI, theory of planned behaviour constructs and food consumption behaviour. Values reported are unstandardised path coefficients. Age and gender were included in the analysis while they were not displayed in the figure. Solid lines show significant associations $\left({ }^{\star} P<0.05,{ }^{\star \star} P<0.01,{ }^{* \star *} P<0.001\right.$ ), and dotted lines show non-significant associations. $B$ (unstandardised) regression estimates. HFI, home fruits and vegetables inventory; F\&V, fruits and vegetables; $P B C$, perceived behavioural control

acceptable fit $\left(\chi^{2}(111)=167 \cdot 23, P<0.001\right.$; RMSEA (root mean square error of approximation) $=0.049$; CFI (comparative fit index $)=0.961$; TLI $($ Tucker-Lewis Index $)=0.947$; GFI (goodness of fit index) $=0.922$; SRMR (standardised root mean square residual) $=0.051$ )

The path analysis revealed that taken as a set, attitude, subjective norm, PBC and intention mediated the effect of HFI on F\&V consumption behaviour as the total indirect effect through the four mediators is different from zero (total indirect effect $=0.354$, bootstrap CI 0.124, 0.643, $P=0.001)$. The directions from the independent variable to the mediators and then to the dependent variable are consistent in that greater HFI led to more positive attitude towards F\&V, subjective norm and $\mathrm{PBC}$, which in turn were linked to greater intention to consume $\mathrm{F} \& \mathrm{~V}$ and greater F\&V consumption behaviour.

Examination of the specific indirect effects showed that the relationship between HFI and F\&V consumption behaviour was mediated through two mediators of PBC, and then intention ( $B=0.06,95 \% \mathrm{CI} 0.007,0 \cdot 194, P<0.05)$. TPB also posits that PBC directly predicts behaviour; however, we did not find significant indirect effects from HFI to F\&V consumption behaviour through only PBC. These findings suggest that high level of HFI was linked to higher PBC $(B=0.25, P<0.05)$, and in turn higher intention to consume $\mathrm{F} \& \mathrm{~V}(B=0.41, P<0.001)$, and subsequently higher $\mathrm{F} \& \mathrm{~V}$ consumption $(B=0.57, P<0.01)$.
The specific indirect effects from HFI to F\&V consumption behaviour through two mediators of attitude and intention were significant $(B=0.03,95 \%$ CI 0.000 , $0 \cdot 115, P<0.05)$. This indicates that higher level of HFI was associated with more positive attitude towards F\&V $(B=0 \cdot 17, P=0 \cdot 10)$, and in turn greater intention $(B=0 \cdot 26$, $P<0.01)$, and then greater consumption of $\mathrm{F} \& \mathrm{~V}(B=0.57$, $P<0 \cdot 01)$. Even though the path from HFI to attitude was NS, the mediation effect was possible because as noted by Preacher \& Hayes ${ }^{(78)}$, the interpretation of the mediation analysis was determined by the direction and size of the indirect effects, rather than the statistical significance of the paths between the independent variable to mediator and between the mediator to the dependent variable as usually requisite by the causal step method ${ }^{(79)}$.

The specific indirect effects from HFI to F\&V consumption behaviour through subjective norm and intention as mediators were not found to be significant, and hence, subjective norm did not mediate the relationship between HFI and F\&V consumption behaviour.

\section{Discussion}

The present research aimed to examine the relationship between F\&V availability at home and F\&V intake among young people, and how this relationship could potentially 
be mediated by individual-level cognitive factors, as outlined in our study framework by the TPB. The findings revealed that home $F \& V$ availability and $F \& V$ consumption behaviour did not show a significant direct association but demonstrated significant indirect links through the routes of PBC and intention as well as via attitude and intention. Specifically, higher levels of F\&V availability at home were related to greater attitude and $\mathrm{PBC}$, and subsequently greater intention to consume $\mathrm{F} \& \mathrm{~V}$ and higher consumption of F\&V.

Unlike past studies which indicate that food availability is a determinant for $F \& V$ consumption ${ }^{(46,58)}$, the present study did not find a significant direct association as hypothesised. The method in which home F\&V availability was measured and analysed in different studies may have contributed to the disparity in the results. For instance, in a few studies where direct association was found ${ }^{(46,48)}$, home F\&V availability was self-reported based only on one or two items, while our study relied on an objective measurement of home F\&V availability. The self-report measure can thus be subjected to social desirability bias ${ }^{(29)}$. Additionally, past research has shown low disagreement between young people's and parents' responses on food availability at home ${ }^{(26-28)}$.

Of interest is the significant indirect effect between home F\&V availability and F\&V consumption behaviour. Attitude, operationalised as positive affect towards F\&V in this study, was found to mediate the relationship between home F\&V availability and F\&V behaviour among young people through intention. Out of all of the TPB constructs, attitude has been most often discovered to be the strongest predictor of dietary intention ${ }^{(24,38)}$, suggesting its critical role in enhancing intention and the necessity to continue the emphasis on building up positive affect towards F\&V. When the availability of F\&V at home is high, it is likely that children and adolescents are exposed more to these foods, and the experience of F\&V being available at home may enable young people to familiarise with these food items and improve their liking towards $F \& V^{(67,80,81)}$.

Our study found that the relationship of home F\&V availability with $\mathrm{F} \& \mathrm{~V}$ behaviour was mediated by PBC and intention, but PBC alone did not significantly mediate this relationship. The pattern of results is in line with metaanalyses which have shown intention to be the strongest predictor of behaviour, stronger than the relationship between PBC and behaviour ${ }^{(24,38)}$. Ajzen ${ }^{(22)}$ has also postulated that intention would act as the strongest determinant of F\&V dietary behaviour when an individual perceives that achieving that behaviour is under his/ her volitional control. In the same vein, $\mathrm{PBC}$ has been found to be a strong predictor of dietary intention ${ }^{(24,38)}$, although findings have admittedly been mixed among young people ${ }^{(39-42)}$. These findings imply that in homes where $F \& V$ tends to be readily available, young people may have a higher sense of control about obtaining $\mathrm{F} \& \mathrm{~V}$ on demand, and this may be linked to greater intention to consume $\mathrm{F} \& \mathrm{~V}$, and subsequently higher intake of $\mathrm{F} \& \mathrm{~V}$. Indeed, food availability has been cited as one of the important control issues with regard to healthy eating and food choice especially among young people ${ }^{(6)}$.

Perceived norms have generally been considered to be a weaker predictor of healthy eating ${ }^{(82-84)}$, and this was also the case for our findings where subjective norm did not significantly mediate the relationship between HFI and F\&V consumption behaviour. It is difficult to measure social pressure as social norms can be operationalised in multiple facets such as descriptive norms and injunctive norms ${ }^{(85)}$. In addition, the degree to which individuals in the home environment (e.g. father, mother, siblings and other relatives) exert influences may also be different. Hence, future research could attempt to differentiate the types of norms and influencers involved when assessing the effect of the subjective norm construct.

\section{Theoretical implications}

The present study contributes to existing literature by integrating the influence of environmental factors with individual-level cognitive factors on $F \& V$ consumption. Specifically, we examined how the TPB constructs could mediate the relationship between home F\&V availability and young people's F\&V consumption.

This research undertook a recording of home food inventory by direct observation at home instead of respondents' self-report. Our approach provided more reliable and accurate home food inventory data, overcoming the social desirability bias issue commonly occurring with parents' self-report method ${ }^{(29)}$. The study also determined the quantity of F\&V found in the home inventory, instead of merely indicating the presence and non-presence of certain food items and, hence, allowing for the examination of how different levels of F\&V inventory at homes could differentially influence F\&V consumption. Nonetheless, direct observation in participants' homes to record their home food inventory was a laborious and potentially intrusive process for both participants and researchers, resulting in a fairly limited sample size for the present study which has prevented the inclusion of various other potential mediators.

\section{Practical implications}

We can derive a number of practical implications from the present study's findings. Firstly, as shown in existing literature, a higher level of F\&V consumption has been associated with lower susceptibility to obesity ${ }^{(6)}$, heart disease ${ }^{(86)}$ and certain forms of cancer $^{(87)}$. Childhood consumption of $\mathrm{F} \& \mathrm{~V}$ has also been found in prior studies to predict $\mathrm{F} \& \mathrm{~V}$ consumption during adulthood ${ }^{(88)}$. In view of these, it is important that young people are encouraged to consume sufficient servings of F\&V every day. Making F\&V readily available at homes could therefore be one of the strategies that parents should implement as another form of encouragement to their children towards consistent consumption 
of $\mathrm{F} \& \mathrm{~V}$, as doing so could enhance young people's sense of control, positive attitude towards F\&V and intention to consume F\&V.

\section{Limitations of the study}

This study is not without several limitations. First, with the exception of the HFI, all other measures were self-reported. This may have resulted in information biases such as overestimation of typical F\&V consumption behaviour from the child survey. Social desirability may have influenced these self-reported measures, especially since young people in Singapore are relatively exposed to the benefits of consuming sufficient F\&V as part of a healthy diet through health promotion initiatives such as My Healthy Plate ${ }^{(89)}$. Second, participants were asked for their intention to consume F\&V in the upcoming week whereas the consumption behaviour items asked participants for their F\&V consumption in a typical week. While participant intention was statistically associated with F\&V consumption (as posited by the TPB), the nature of these items and the cross-sectional design of the present study should be taken into consideration in any extrapolation of our findings. Last, we examined associations among F\&V availability in the household, young peoples' intrapersonal mediators based on the TPB and F\&V consumption behaviour based on the EnRG model. While our findings support the literature on the important role of $\mathrm{F} \& \mathrm{~V}$ availability ${ }^{(51)}$, we recognise that the food environment is complex, and our findings do not account for other environmental factors that may have influenced these observed associations.

\section{Conclusion}

Our study examined how environmental factor could have an impact on young people's consumption behaviour through the mediation of individual-level cognitive factors as outlined by TPB. We found that F\&V availability at home was indirectly associated with young people's F\&V consumption behaviour through the $\mathrm{PBC}$ and intention path as well as the attitude and intention path. Our findings provide a foundational contribution towards unravelling the environmental processes involved in influencing young people's healthy food intake.

\section{Acknowledgements}

Acknowledgements: None. Financial support: This study was supported by the National Medical Research Council, Singapore (grant no. NMRC/HSRG/0046/2013). Conflict of interest: There are no conflicts of interest. Authorship: M.O.L. and S.M. conceptualised the present work; S.M. and J.L. performed article search and data analysis and drafted the initial version of the manuscript; J.L. coordinated the data collection; all authors contributed towards further revisions of the paper and approved the final version of the manuscript before submission. Ethics of human subject participation: This study was conducted according to the guidelines laid down in the Declaration of Helsinki and all procedures involving human subjects were approved by the Nanyang Technological University Institutional Review Board. Written informed consent was obtained from all subjects.

\section{References}

1. Ng M, Fleming T, Robinson M et al. (2014) Global, regional, and national prevalence of overweight and obesity in children and adults during 1980-2013: a systematic analysis for the Global Burden of Disease Study 2013. Lancet $\mathbf{3 8 4}$, 766-781.

2. Singapore risks hitting obesity rates of $15 \%$ in seven years. https://www.straitstimes.com/singapore/singapore-riskshitting-obesity-rates-of-15-in-seven-years (accessed January 2019).

3. Ministry of Health Singapore (2017) Executive Summary on National Population Health Survey 2016/17. https://www. moh.gov.sg/docs/librariesprovider5/resources-statistics/ reports/executive-summary-nphs-2016_17.pdf (accessed November 2019).

4. McMahon SK, Haynes A, Ratnam N et al. (2004) Increase in type 2 diabetes in children and adolescents in Western Australia. Med J Aust 180, 459-461.

5. Roberts M \& Pettigrew S (2013) Psychosocial influences on children's food consumption. Psychol Market 30, 103-120.

6. Backman DR, Haddad EH, Lee JW et al. (2002) Psychosocial predictors of healthful dietary behavior in adolescents. J Nutr Educ Behav 34, 184-193.

7. Mossberg HO (1989) 40-year follow-up of overweight children. Lancet 2, 491-493.

8. Must A, Jacques PF, Dallal GE et al. (1992) Long-term morbidity and mortality of overweight adolescents. A followup of the Harvard Growth Study of 1922 to 1935. N Engl J Med 327, 1350-1355.

9. Livingstone S \& Helsper EJ (2004) Advertising Foods to Children: Understanding Promotion in the Context of Children's Daily Lives. London: Office of Communications (OFCOM).

10. Bel-Rastrollo M, Martinez-Gonzalez MA, Sanchez-Villegas A et al. (2006) Association of fiber intake and fruit/vegetable consumption with weight gain in a Mediterranean population. Nutr Rev 22, 504-511.

11. Rolls BJ, Ello-Martin JA \& Tohill BC (2004) What can intervention studies tell us about the relationship between fruit and vegetable consumption and weight management? Nutr Rev 62, $1-17$.

12. Tohill BC, Seymour J, Serdula M et al. (2004) What epidemiologic studies tell us about the relationship between fruit and vegetable consumption and body weight. Nutr Rev $\mathbf{6 2}$, 365-374.

13. United States Department of Agriculture (USDA) (2018) MyPlate: All About the Fruit Group. https://www. choosemyplate.gov/fruit (accessed January 2019).

14. Health Promotion Board (2015) Harness the Goodness of Fruit and Vegetables. https://www.healthhub.sg/livehealthy/514/Benefits\%20of\%20Fruit\%20and\%20Vegetables (accessed January 2019).

15. Guenther PM DK, Reedy J \& Krebs-Smith SM (2006) Most Americans eat much less than recommended amounts of fruits and vegetables. J Am Diet Assoc 106, 1371-1379. 
16. World Health Organisation (2015) Healthy Diet: Fact Sheet No. 394. http://www.who.int/nutrition/publications/ nutrientrequirements/healthydiet_factsheet/en/ (accessed January 2019).

17. Singaporeans are not eating enough vegetables - and health experts know why. https://cnalifestyle.channelnewsasia. com/wellness/are-singaporeans-eating-enough-vegetables10706014 (accessed January 2019).

18. Dauchet L, Amouyel P \& Dallongeville J (2009) Fruits, vegetables and coronary heart disease. Nat Rev Cardiol 6, 599-608.

19. Kothe EJ, Mullan BA \& Butow P (2012) Promoting fruit and vegetable consumption. Testing an intervention based on the Theory of Planned Behaviour. Appetite 58, 997-1004.

20. Emanuel AS, McCully SN, Gallagher KM et al. (2012) Theory of Planned Behavior explains gender difference in fruit and vegetable consumption. Appetite 59, 693-697.

21. Blanchette L \& Brug J (2005) Determinants of fruit and vegetable consumption among 6-12-year-old children and effective interventions to increase consumption. J Hum Nutr Diet 18, 431-443.

22. Ajzen I (1991) The Theory of Planned Behavior. Organ Behav Hum Decis Process 50, 179-211.

23. Painter JE, Borba CPC, Hynes M et al. (2008) The use of theory in health behavior research from 2000 to 2005: a systematic review. Ann Behav Med 35, 358-362.

24. Riebl SK, Estabrooks PA, Dunsmore JC et al. (2015) A systematic literature review and meta-analysis: the Theory of Planned Behavior's application to understand and predict nutrition-related behaviors in youth. Eat Behav 18, 160-178.

25. Webb TL, Joseph J, Yardley L et al. (2010) Using the Internet to promote health behavior change: a systematic review and meta-analysis of the impact of theoretical basis, use of behavior change techniques, and mode of delivery on efficacy. J Med Internet Res 12, e4.

26. Reinaerts E, de Nooijer J \& de Vries NK (2007) Parental versus child reporting of fruit and vegetable consumption. Int $J$ Behav Nutr Phys Act 4, 33

27. Tak NI, te Velde SJ, de Vries JHM et al. (2006) Parent and child reports of fruit and vegetable intakes and related family environmental factors show low levels of agreement. J Hum Nutr Diet 19, 275-285.

28. van Assema P, Glanz K, Martens M et al. (2007) Differences between parents' and adolescents' perceptions of family food rules and availability. J Nutr Educ Behav 39, 84-89.

29. Pinard CA, Yaroch AL, Hart MH et al. (2012) Measures of the home environment related to childhood obesity: a systematic review. Public Health Nutr 15, 97-109.

30. Hewitt AM \& Stephens C (2007) Healthy eating among 10-13-year-old New Zealand children: understanding choice using the Theory of Planned Behaviour and the role of parental influence. Psychol Health Med 12, 526-535.

31. Backman DR, Haddad EH, Lee JW et al. (2002) Psychosocial predictors of healthful dietary behavior in adolescents. J Nutr Educ Behav 34, 184-192.

32. Kida IA \& Åstrøm AN (1998) Correlates of the intention to avoid intake of sugared snacks among Tanzanian adolescents. J Gender Cult Health 3, 171-182.

33. Masalu JR \& Åstrøm AN (2001) Predicting intended and selfperceived sugar restriction among Tanzanian students using the Theory of Planned Behavior.J Health Psychol 6, 435-445.

34. Armitage CJ \& Conner M (2001) Efficacy of the Theory of Planned Behaviour. A meta-analytic review. Br J Soc Psychol 40, 471-499.

35. Berg C, Jonsson I \& Conner M (2000) Understanding choice of milk and bread for breakfast among Swedish children, aged 11-15 years: an application of the Theory of Planned Behavior. Appetite 34, 5-19.

36. Guillaumie L, Godin G \& Vezina-Im LA (2010) Psychosocial determinants of fruit and vegetable intake in adult population: a systematic review. Int J Behav Nutr Phys Act 7, 12.
37. Lautenschlager L \& Smith C (2007) Understanding gardening and dietary habits among youth garden program participants using the Theory of Planned Behavior. Appetite 49, 122-130.

38. McDermott MS, Oliver M, Simnadis T et al. (2015) The Theory of Planned Behaviour and dietary patterns: a systematic review and meta-analysis. Prev Med 81, 150-156.

39. Chan K \& Tsang L (2011) Promote healthy eating among adolescent: a Hong Kong study. J Consum Mark 28, 354-362.

40. Grønhøj A, Bech-Larsen T, Chan K et al. (2013) Using Theory of Planned Behavior to predict healthy eating among Danish adolescents. Health Edu 113, 4-17.

41. Branscum P \& Sharma M (2011) Using the Theory of Planned Behavior to predict two types of snack food consumption among Midwestern upper elementary children; Implications for practice. Health Promot Pract 15, 134-140.

42. Hewitt AM \& Stephens C (2007) Healthy eating among 10-13-year-old New Zealand children: understanding choice using the Theory of Planned Behaviour and the role of parental influence. Psychol Health Med 12, 526-535.

43. Blanchard CM, Fisher J, Sparling PB et al. (2009) Understanding adherence to 5 servings of fruits and vegetables per day: a Theory of Planned Behavior perspective. J Nutr Educ Behav 41, 3-10.

44. Brug J, de Vet E, de Nooijer J et al. (2006) Predicting fruit consumption: cognitions, intention, and habits. J Nutr Educ Behav 38, 73-81.

45. Bogers RP, Brug J, van Assema P et al. (2004) Explaining fruit and vegetable consumption: the Theory of Planned Behaviour and misconception of personal intake levels. Appetite $\mathbf{4 2}$, 157-166.

46. Reinaerts E, de Nooijer J, Candel M et al. (2007) Explaining school children's fruit and vegetable consumption: the contributions of availability, accessibility, exposure, parental consumption and habit in addition to psychosocial factors. Appetite 48, 248-258.

47. Brug J (2008) Determinants of healthy eating: motivation, abilities and environmental opportunities. Fam Pract 25, Suppl. 1, i50-i55.

48. Giskes K, van Lenthe FJ, Kamphuis CB et al. (2009) Household and food shopping environments: do they play a role in socioeconomic inequalities in fruit and vegetable consumption? A multilevel study among Dutch adults. J Epidemiol Community Health 63, 113-120.

49. van der Horst K, Timperio A, Crawford D et al. (2008) The school food environment associations with adolescent soft drink and snack consumption. Am J Prev Med 35, $217-223$

50. Gorin AA, Phelan S, Raynor H et al. (2011) Home food and exercise environments of normal-weight and overweight adults. Am J Health Behav 35, 618-626.

51. Rosenkranz RR \& Dzewaltowski DA (2008) Model of the home food environment pertaining to childhood obesity. Nutr Rev 66, 123-140.

52. Ong JX, Ullah S, Magarey A et al. (2017) Relationship between the home environment and fruit and vegetable consumption in children aged 6-12 years: a systematic review. Public Health Nutr 20, 464-480.

53. Rasmussen M, Krolner R, Klepp KI et al. (2006) Determinants of fruit and vegetable consumption among children and adolescents: a review of the literature. Part I: quantitative studies. Int J Behav Nutr Phys 3, 22.

54. Haire-Joshu D, Elliott MB, Caito NM et al. (2008) High 5 for Kids: the impact of a home visiting program on fruit and vegetable intake of parents and their preschool children. Prev Med 47, 77-82.

55. Hearn MD, Baranowski T, Baranowski J et al. (1998) Environmental influences on dietary behavior among children: availability and accessibility of fruits and vegetables enable consumption. J Health Educ 29, 26-32. 
56. Gebremariam MK, Vaque-Crusellas C, Andersen LF et al. (2017) Measurement of availability and accessibility of food among youth: a systematic review of methodological studies. Int J Behav Nutr Phys 14, 1-19.

57. Boles RE, Scharf C, Filigno SS et al. (2013) Differences in home food and activity environments between obese and healthy weight families of preschool children. $J$ Nutr Educ Behav 45, 222-231.

58. Trapp GS, Hickling S, Christian HE et al. (2015) Individual, social, and environmental correlates of healthy and unhealthy eating. Health Educ Behav 42, 759-768.

59. Kamphuis CB, Giskes K, de Bruijn GJ et al. (2006) Environmental determinants of fruit and vegetable consumption among adults: a systematic review. Br J Nutr 96, 620-635.

60. Kratt P, Reynolds K \& Shewchuk R (2000) The role of availability as a moderator of family fruit and vegetable consumption. Health Educ Behav 27, 471-482.

61. Tak NI, te Velde SJ, Kamphuis CBM et al. (2012) Associations between neighbourhood and household environmental variables and fruit consumption: exploration of mediation by individual cognitions and habit strength in the GLOBE study. Public Health Nutr 16, 505-514.

62. Domel SB, Baranowski T, Davis H et al. (1993) Development and evaluation of a school intervention to increase fruit and vegetable consumption among 4 th and 5th grade students. J Nutr Educ 25, 345-349.

63. Bere E \& Klepp KI (2005) Changes in accessibility and preferences predict children's future fruit and vegetable intake. Int J Behav Nutr Phys 2, 15.

64. Yee AZH, Lwin MO \& Ho SS (2017) The influence of parental practices on child promotive and preventive food consumption behaviors: a systematic review and meta-analysis. Int J Behav Nutr Phys 14, 47.

65. Singapore Urban Redevelopment Authority (n.d.) Master Plan. https://www.ura.gov.sg/Corporate/Planning/MasterPlan (accessed March 2015).

66. Brown R \& Ogden J (2004) Children's eating attitudes and behaviour: a study of the modelling and control theories of parental influence. Health Educ Res 19, 261-271.

67. Cooke LWJ \& Gibson EL (2003) Relationship between parental report of food neophobia and everyday food consumption in 2-6-year-old children. Appetite 41, 205-206.

68. Thompson FEKV, Subar AF, Krebs-Smith SM et al. (2000) Evaluation of 2 brief instruments and a food-frequency questionnaire to estimate daily number of servings of fruit and vegetables. Am J Clin Nutr 71, 1503-1510.

69. National Cancer Institute (2011) FAB Analytic Guidance Document. https://cancercontrol.cancer.gov/brp/hbrb/fab/ docs/FAB_analytic_guide_doc_final_4-26.pdf (accessed April 2017).

70. Subar AF, Thompson FE, Kipnis V et al. (2001) Comparative validation of the Block, Willett, and National Cancer Institute food frequency questionnaires - the eating at America's table study. Am J Epidemiol 154, 1089-1099.

71. Aikman SN, Crites SL \& Fabrigar LR (2006) Beyond affect and cognition: identification of the informational bases of food attitudes. J Appl Soc Psychol 36, 340-382.
72. Fishbein M \& Ajzen I (2010) Predicting and Changing Behavior: The Reasoned Action Approach. New York, NY: Psychology Press.

73. Bryant M \& Stevens J (2006) Measurement of food availability in the home. Nutr Rev 64, 67-76.

74. Kremer PJ, Bell AC \& Swinburn BA (2006) Calibration and reliability of a school food checklist: a new tool for assessing school food and beverage consumption. Asia Pac J Clin Nutr 15, 465-473.

75. IBM Corporation (2013) IBM SPSS Statistics for Windows, Version 22.0. Armonk, NY: IBM Corp.

76. Jaramillo SJ, Yang SJ, Hughes SO et al. (2006) Interactive computerized fruit and vegetable preference measure for African-American and Hispanic preschoolers. J Nutr Educ Behav 38, 352-359.

77. Di Noia J \& Cullen KW (2015) Fruit and vegetable attitudes, norms, and intake in low-income youth. Health Education Behav 42, 775-782.

78. Preacher KJ \& Hayes AF (2008) Asymptotic and resampling strategies for assessing and comparing indirect effects in multiple mediator models. Behav Res Method 40, 879-891.

79. Baron RM \& Kenny DA (1986) The moderator-mediator variable distinction in social psychological research: conceptual, strategic, and statistical considerations.J Pers Soc Psychol 51, $1173-1182$

80. Capaldi ED (1996) Why We Eat What We Eat: The Psychology of Eating. Washington, DC: American Psychological Association.

81. Birch LL \& Fisher JA (1995) Appetite and eating behavior in children. Pediatr Clin North Am 42, 931-953.

82. Louis WR, Chan MKH \& Greenbaum S (2009) Stress and the Theory of Planned Behavior: understanding healthy and unhealthy eating intentions. J Appl Soc Psychol 39, 472-493.

83. Paisley CM \& Sparks P (1998) Expectations of reducing fat intake: the role of perceived need within the Theory of Planned Behaviour. Psychol Health 13, 341-353.

84. Shaikh AR, Yaroch AL, Nebeling L et al. (2008) Psychosocial predictors of fruit and vegetable consumption in adults a review of the literature. Am J Prev Med 34, 535-543.

85. Armitage CJ \& Conner M (2001) Efficacy of the Theory of Planned Behaviour: a meta-analytic review. BrJ Soc Psychol 40, 471-499.

86. Hu FB (2003) Planted-based foods and the prevention of cardiovascular disease. An overview. Am J Clin Nutr 78, 544S-551S

87. Steinmetz KA \& Potter JD (1996) Vegetables, fruit, and cancer prevention: a review. J Am Diet Assoc 96, 1027-1039.

88. Edwards JSA \& Hartwell HH (2002) Fruit and vegetables attitudes and knowledge of primary school children. J Hum Nutr Diet 15, 365-374.

89. Health Promotion Board (2019) My Healthy Plate. https:// www.healthhub.sg/programmes/55/my-healthy-plate (accessed January 2019). 